\title{
AÇÃo DO CEPA E DO ÁCIDO GIBERÉLICO NA FRUTIFICAÇÃo DA VIDEIRA 'NIAGARA ROSADA" *
}

\author{
PAUlo R.C. CASTRO**
}

\section{PESUMO}

Estudou-se o efeito da aplicação, por imersão, do CEPA (ácido 2-cloroetil fosfônico) e do ácido giberélico, 14 dias antes do florescimento, nas características morfológicas da panícula da videira Vitis (labrusca $x$ vinifera) "Niagara Rosada". Alguns tratamentos com ácido giberélico foram concluídos com nova aplicaçẫo 10 dias após o florescimento. Neste experimento verificou-se que, aplicação do CEPA na concentração de $250 \mathrm{ppm}$ resultou na formação de panículas com a maioria de características indesejáveis. $O$ tratamento misto CEPA $100 \mathrm{ppm}+$ ácido giberélico $100 \mathrm{ppm}$ também promoveu o aparecimento de panículas subdesenvolvidas.

Aplicação de ácido giberélico na concentração de 100 ppm em pré e pós-florescimento, resultou médias mais elevadas, com relação ao peso da panícula, comprimento da panícula, peso das bagas e comprimento da ráquis. Ácido giberélico na concentração de $100 \mathrm{ppm}$ aplicado em pós-florescimento, promoveu uma tendência de aumento nas médias do tratamento quanto ao comprimento médio das bagas, largura média das bagas, largura do engaço e comprimento da ráquila.

Devemos considerar porém, que os resultados obtidos não apresentaram diferenças significativas com relação ao controle, quanto às características das frutificaçōes, nas condições de estudo.

A Vitis (labrusca $x$ vinifera) 'Niagara Rosada 'é a cultivar mais consumida como uva de mesa do Brasil; sendo que a produção verifica-se no periodo de novembro a março, colhendo-se $17 \%$ no mês de dezembro, $67 \%$ em janeiro, e $15 \%$ ern fevereiro; sendo que o restante é produzido nos meses de março e novembro (ARRUDA NETO, 1970).

As cultivares para mesa devem apresentar certas características para sua aceitação zomercial. A apresentação é uma das principais características, devendo a panícula ser grande, vistosa, com bagas distanciadas uma das outras, sendo estas de tamanho grande, bonito colorido e sem defeitos. Outra importante caracteristica que as cultivares para mesa devem apresentar é alta resistência ao transporte; sendo que precocidade de maturação também é qualidade desejável para uvas de mesa. A "Niagara Rosada" não se apresenta com resistência adequada ao transporte e armazenamento; além disso a panícula apresenta-se variável $\mathrm{em}$ tamanho, forma e compacidade (SOUSA, 1969).

A videira cultivar "Niagara Branca ' originou-se a partir de uma planta de "Concord'

\footnotetext{
* Entregue para publicação em 21/7/1975.

** Departamento de Botânica. E.S.A. "Luiz de Queiroz"'iUSP.
} 
(Vitis labrusca) polinizada com 'Cassady' (Vitis labrusca L. x Vitis vinifera L.) em 1868 (HEDRICK, BOOTH \& TAYLOR, 1908). Deste modo, resultou de um retrocruzamento do híbrido interespecifico $V$. labrusca $x V$. vinifera com $V$. labrusca (MUNSON, 1909; HUSMANN, 1932).

Introduziu-se a 'Niagara Branca' no Brasil, mais precisamente, no Estado de São Paulo, em 1894, por meio de bacelos recebidos do Estado do Alabama, nos Estados Unidos da América do Norte. Pelo ano de 1910 começou a ser conhecida como variedade comercial e a partir de 1934 iniciou-se sua rápida expansão como uva de mesa (SOUSA, 1959a).

Deve-se assinalar que a complexidade de antecessores conferiu à cultivar fatores genéticos instáveis. Assim sendo, ocorreram no Brasil algumas mutações somáticas, sendc que em 1933, teve-se a principal delas, quando em Louveira, Estado de São Paulo, descobriu-se uma planta de 'Niagara Branca', enxertada sobre 'Herbemont' (Vitis aestivalis 'Bourquiniana'), que apresentava uma panicula de bagas inteiramente rosadas. Marcado o bacelo do qual nascera a panícula, fez-se com ele alguns enxertos que produziram panículas de 'Niagara Rosada'. Por sucessivas propagações vegetativas a nova cultivar difundiu-se rapidamente e tornou-se a uva de mesa mais extensamente cultivada no Brasil (SOUSA, 1959b).

Há, mesmo nos Estados Unidos da América do Norte, que contam com vultuosa produção de Vitis vinifera da Califórnia, ponderável parte de sua população que realmente aprecia o sabor e o aroma foxado consumindo grandes produções originárias de Vitis labrusca, considerando o foxado desses produtos uma caracteristica de grande valor organoléptico (HEDRICK, BOOTH \& TAYLOR, 1908; SHAULIS, 1950).

A ' Niagara Rosada' trata-se de videira precoce de vigor médio, que se adapta ao espaçamento de $2 \mathrm{~m}^{2}$ quando conduzida em espaldeira de três fios e poda curta. Apresenta-se razoavelmente tolerante e alguns agentes causadores de doenças fúngicas comuns em nossas condições, sendo normalmente suficientes oito pulverizações preventivas para a manutenção do bom estado de sanidade da cultura (PEREIRA, 1972).

WEAVER \& POOL (1965) analisaram extratos de flores, bagas ou ambos, de 5 cultivares de Vitis vinifera, para atividade semelhante à giberelina. Encontraram em todas as cultivares testadas, e pelo menos em certas instâncias, em todas as frações testadas. Em duas cultivares em que existiam formas com e sem sementes, a atividade estava presente nos dois materiais em estudo. Há maior atividade semelhante à giberelina em 'Tokay' com sementes, em relação à cultivar aspérmica.

IWAHORI, WEAVER \& POOL (1968) determinaram atividade de substância semelhante à giberelina em bagas das videiras 'Tokay 'e 'Seedless Tokay ' em diferentes estágios do desenvolvimento. Nas bagas com sementes havia atividade muito alta que iniciava no estágio de fixação do fruto e persistia por cerca de três semanas; sendo que após este periodo a atividade descia para nível baixo e desaparecia na metade de julho. No início de agosto havia outro pico de atividade. A atividade em 'Seedless Tokay' mostrou-se semelhante, exceto o declínio que foi consideravelmente mais rápido, $\mathrm{e} o$ pico secundário alcançado em meados de junho, em lugar de agosto.

A importância dos reguladores de crescimento no desenvolvimento da frutificação 
tem sido demonstrada em muitas espécies (CRANE, 1964); sendo que aplicações comerciais destes produtos químicos têm sido realizadas, particularmente na videira, onde são de grande importância econômica. Especialmente cultivares de videiras desprovidas de sementes, haviam mostrado respostas e certos reguladores vegetais (WEAVER \& WILLIAMS, 1950; WEAVER, 1956).

NELJUBOW (1901) mostrou que o etileno é a substância ativa presente no gás de iluminação, responsável por respostas biológicas de vegetais. ZIMMERMANN \& WILCOXON (1935) verificaram que auxina exógena estimula a produção de etileno em diversas plantas. HANSEN \& HARTMAN (1937) observaram efeito do etileno na respiração e no amadurecimento de pêras, antes e após armazenamento sob baixa temperatura. MAXIE \& CRANE (1968) verificaram que o etileno acelera a maturação de frutos de figo, mesmo que estes estejam ainda presos na árvore. Inúmeros experimentos em pós-colheita demonstraram que o etileno é um agente de maturação (PRATT \& GOESCHL, 1969). Considera-se que o etileno produzido na extremidade apical de ramos pode se difundir para regiōes inferiores.

$\mathrm{O}$ etileno, hidrocarboneto simples, é metabólito normal da planta que pode controlar a formação do gancho apical no estiolamento, a iniciação floral em algumas plantas, a abscisão das folhas, a indução do periodo climatérico na respiração do fruto, e os processos subseqüentes relacionados com a maturação (GALSTON \& DAVIES, 1970).

Etileno é presumivelmente derivado do aminoácido metionina e especialmente de seu derivado metional, que podem dar origem ao etileno sob ação da enzima peroxidase ou de riboflavina mononucleotídeo em presença de luz. Ambos os sistemas podem ter importância fisiológica, pois se a peroxidase está entre as enzimas induzidas pelo etileno e por sua vez forma etileno, esta poderá ser a forma pela qual se propaga a produção deste gás de um tecido para outro (HALL \& MORGAN, 1964; YANG, 1969). Não somente as peroxidases produzem etileno, mas algumas isoenzimas de peroxidade são mais ativas a esse respeito. Este pode ser o meio pelo qual auxina promove a formação de etileno, pois ela regula a sintese de certas peroxidases. Do mesmo modo, a produção do etileno sob ação da luz e riboflavina mononucleotídeo, pode apresentar certas implicações no fototropismo (GALSTON \& DAVIES, 1970).

O mecanismo pelo qual o etileno induz a maturação é ainda desconhecido. Umá teoria considera que o etileno modifica o estado físico de células ou membranas, possibilitando a ocorrência de reações que anteriormente não estariam sendo permitidas. $O$ etileno pode ser o agente causal das alterações na permeabilidade celular que ocorrem durante a maturação dos frutos. Este composto estimula a respiração e a síntese de proteínas em certos frutos imaturos, o que pode desencadear uma série de processos bioquímicos necessários para o amadurecimento (WEAVER, 1972).

WEAVER \& POOL (1969) verificaram que aplicação do ácido 2-cloroetano fosfônico em 'Thompson Seedless', nas concentrações de 100 e 1000 ppm produz abscisão em 70 e $90 \%$ respectivamente, sendo que baixas concentrações não produzem efeito significativo. Esses autores observaram ainda redução no peso das panículas, número de bagas e peso das bagas de "Muscat of Alexandria", pela aplicação de CEPA nas concentrações de 100 e 1000 ppm.

HALE, COOMBRE \& HAWKER (1970) verificaram que a imersão de panículas do 
cultivar 'Doradillo' em CEPA adiantou em 6 dias a maturação; sendo que para a cultivar 'Shiraz' pode-se obter 4 dias de antecipação. A concentração de 500 ppm mostrou-se mais efetiva que a dosagem de 1200 ppm. Verificaram ainda que duas indicações de maturação podem ser observadas: aceleração no desenvolvimento e aumento na relação açúcar/acidez.

WEAVER \& POOL (1971) efetuaram aplicação de CEPA nas concentrações de 200 a $2000 \mathrm{ppm}$ sobre as cultivares 'Tokay' e 'Emperor', e de $1000 \mathrm{ppm}$ sobre 'Thompson Seedless' e ' 'arignane'. duas semanas antes do início da coloração. Observaram aumento significativo de sólicios solúveis em alguns frutos de 'Carignane '; sendo que 0 composto promoveu reduções na acidez, em alguns frutos das cultivares estudadas. 0 correu aumento no teor de aniscianina das bagas, mas não tão significativo como em. 'Tokay'.

WEAVER \& MONTGOMERY (1972) verificaram que as cultivares 'Barbera' e 'Grenache' são afetadas somente por aplicaçбes precoces de CEPA, que antecipam a coloração das bagas. Observaram que 'Zinfandel 'é igualmente afetada por aplicações precoces ou tardias. Os tratamentos precoces resultaram em altos niveis de coloração em 'Ruby Cabernet', sendo que a concentração de 1000 ppm do composto foi mais efetiva que a de $300 \mathrm{ppm}$. Ocorreu ainda significativa redução na acidez total em frutos da cultivar 'Grenache ' tratados com CEPA.

Desde que demonstrou-se no Japão a presença de um estimulante de crescimento em filt rados de Fusarium moniliforme (KUROSAWA, 1926) iniciaram-se estudos para estabelecer a natureza química do estímulo. Esses estudos levaram ao isolamento de um produto cristalino, cuja aplicação estimulava o crescimento de raizes de plântulas (YABUTA \& HAYASHI, 1939).

Giberelinas são definidas como compostos que possuem o esqueleto do enantiômero de giberelano (ROWE, 1968) e atividade biológica em estimular a divisão celular ou a elongação celular, ou ambos, ou qualquer outra atividade biológica semelhante (iniciação ou estimulação de sıntese de enzima e outras) que possa ser associada especificamente com este tipo de substância de ocorrência natural (PALEG, 1965). Giberelina é um composto isoprenóide formado de diterpenos, os quais são metabólitos bem conhecidos de angiospermas. Acredita-se que em plantas superiores, os precursores imediatos de giberelina sejam caureno ou esteviol, variando provavelmente com a espécie (WEST et al., 1969; RUDDAT, 1969).

Desde que mostrou-se a habilidade da giberelina em estimular o desenvolvimento das panículas em videira (WEAVER \& OLMO, 1957), o produto tem sido largamente utilizado, principalmente em Vitis vinifera 'Thompson Seedless' (WEAVER \& McCUNE, 1959a).

Como uma das respostas mais características dos vegetais à giberelina é o aumento em comprimento das brotações, ênfase particular deve ser dada cos seus efeitos no comprimento e diâmetro do pedúnculo, ráquis e ráquilas (WEAVER \& McCUNE, 1959b).

KISHI \& TASAKI (1958) verificaram que imersão das panículas da cultivar 'Delaware', 15 dias antes do florescimento e 30 dias após a primeira aplicação, promove precocidade na maturação, aumento no peso das panículas e no número de bagas. 
HALSEY (1959) observou que a aplicação de giberelina na dosagem de $100 \mathrm{ppm}$, em pós-florescimento, sobre as cultivares 'Thompson Seedless' e 'Beauty Seedless ', promove aumento no tamanho das bagas em cerca de $50 \%$. Verificou ainda decréscimo na concentração de açúcar proporcional ao aumento nas dimensões das bagas promovido pelo regulador de crescimento. Verificou-se aumento apreciável na produção de Vitis vinifera cultivar "' 'usa Seedless', pela aplicação de ácido gibe rélico (KRISHNAMURTHI, RANDHAWA \& SINGH, 1959).

LAVEE (1960) verificou o efeito da aplicação de giberelina a 20 ppm, 23 dias antes do florescimento, na cultivar 'Queen of Vinyard', observando incremento no tamanho dos frutos; porém os aumentos adicionais decresceram com a elevação no número de ementes. A giberelina possui um efeito fisiológico nas bagas com sementes, mas somenie até certo limite. A giberelina compensa a carência de sementes; mas quando a baga possui um número suficiente de sementes, a giberelina na concentração utilizada não apresenta efeito evidente.

SINGH (1961) observou, maior desenvolvimento dos frutos das cultivares 'Delaware ', 'Golden Muscat ' e 'Niagara ', além de aumento no conteúdo de açúcar e redu̧̧ão no número de sementes, pelo tratamento com giberelina antes do florescimento.

PRATT \& SHAULIS (1961) verificaram que giberelina induz o desenvolvimento precoce de bagas partenocárpicas em duas videiras com sementes sob condições de polinização deficiente ou auente. Ocorreu aumento na porcentagern de fixação nas cultivares 'Fredonia' e 'Concord' por aplicações duplas de giberelina nas dosagens de 100 e $200 \mathrm{ppm}$, respectivamente, no periodo de florescimento. Observou-se redução na queda de frutos. As bagas tratadas mostraram-se com maiores dimensões três semanas após o florescimento, mas na colheita elas tenderam a ficar menores que o controle. As bagas partenocárpicas revelaram-se menores do que as que possuíam uma ou mais sementes.

WINKLER (1962) relatou que aplicação de giberelina nas dosagens de 5 a 20 ppm, após a queda das bagas inviáveis, promove aumento no tamanho das bagas da cultivar 'Thompson Seedless '; sendo que CELESTRE (1963) verificou diminuição no peso das bagas, maior resistência da epiderme à ruptura e aumento na resistência do pedúnculo, com aplicação de ácido giberélico sobre a cultivar 'Ohanês", no período de florescimento.

TARANTOLA \& CURZEL (1963) não encontraram nenhum efeito da giberelina aplicada em pós-florescimento sobre a morfologia das panículas de cultivares para vinho. CAJLAHJAN \& SARKIZOVA (1963) aplicando sobre cultivares de videiras com sementes, ácido giberélico nas concentraçðes de 50 e 100 ppm, durante o florescimento, verificaram aumento nos teores de açúcar e de matéria seca.

LIDER \& EINSET (1966) obtiveram aumento de $40 \%$ no peso das panículas da cultivar 'Himrod', 60\% no tamanho das bagas de 'N.Y. 21572' e grande aumento no peso das paniculas e bagas da cultivar ' Interlaken Seedless', pela aplicação de giberelina na concentração de $50 \mathrm{ppm}$, após a queda das bagas inviáveis. ANÔNiMO (1967) verificou que imersão das panículas da cuitivar 'Delaware ' em solução de giberelina na concentração de $100 \mathrm{ppm}, 14$ dias antes do florescimento, promove partenocarpia e precocidade na maturação. Nova aplicação 10 dias após o florescimento mostrou aumento no 
tamanho das bagas.

BORZINI (1968) verificou que aplicação de ácido giberélico sobre três cultivares de videira, em pré-florescimento promoveu aumento no peso das bagas; sendo que o número de bagas por panícula permaneceu constante na maioria dos tratamentos.

CHRISTODOULOU, WEAVER \& POOL (1968) verificaram que com aplicação de ácido giberélico durante o florescimento decresceu o tamanho das bagas de "Carignane' e 'Thompson Seedless', mas não afetou a cultivar 'Black Corinth'. Em aplicação após a antese o regulador de crescimento mostrou pequeno efeito no tamanho das bagas. Tratamentos no florescimento resultaram em notável elongação longitudinal das bagas; sendo que tratamentos posteriores adicionais promoveram expansão radial.

SRIVASTAVA \& BISHT (1969) verificaram que pulverização com giberelina nas concentrações de 20 e $50 \mathrm{ppm}$ sobre cultivares apirenas, após o florescimento, promove redução na abscisão das bagas e aumento no peso, comprimento, largura e número das mesmas; além de aumento nos teores de sólidos solúveis totais.

CELESTRE \& PIERANDREI (1969) verificaram que aplicação de diferentes concentrações de giberelinas, antes da antese, sobre diversas cultivares de videira, promove aceleração da maturação, redução no número de sementes e formação de bagas não desenvolvidas. Observaram que imersão das panículas de 'Beauty Seedless', após a queda das bagas inviáveis, em solução de giberelina na dosagem de $20 \mathrm{ppm}$ aumenta o tamanho das bagas. Estes mesmos autores verificaram ainda que aplicaçð̃es de giberelinas na concentração de $25 \mathrm{ppm}$ no pré-florescimento e $20 \mathrm{ppm}$ em pós-florescimento, resultam em aumento pronunciado no peso das bagas, com relação ao tratamento único.

TULLIO \& SVAMPA (1970) verificaram que tratamentos duplos com giberelina a $20 \mathrm{ppm}$, na cultivar 'Labrusco', promoveram aumento no comprimento da panícula e no teor de açúcares.

$O$ presente trabalho foi efetuado com a finalidade de avaliação dos possiveis efeitos do CEPA e do ácido giberélico nas características morfológicas da panícula da videira 'Niagara Rosada '.

\section{MATERIAIS E MÉTODOS}

Utilizaram-se videiras da cultivar 'Niagara Rosada' (Vitis labrusca L. x Vitis vinifera L.) enxertadas sobre 'Riparia do Traviú '(Riparia x Rupestris 'Cordifolia 106-8', com idade de 20 anos e produçōes médias anuais acima de $2 \mathrm{~kg} / \mathrm{m}^{2}$. Essas videiras, constituind o um conjunto recebendo tratos culturais cuidadosos, estavam localizadas em leve encosta, dispostas em linhas perpendiculares à declividade do terreno, em Louveira, SP. Apresentavam espaçamentos de $2 \times 1 \mathrm{~m}$, sendo conduzidas no sistema de espaldeira de três fios com poda invernal em cordão esporonado. Encontravam-se em um solo que, dentre as unidades mapeadas pela Comissão de Solos em São Paulo, enquadra-se no Podzólico Vermelho Amarelo orto, correspondendo ao subgrupo 'Typic Paleudult' na classificação proposta pelo ' Soil Survey Staff ' (VALADARES, LEPSCH \& KUPPER, 1971). 
Comc fonte de etileno empregou-se o ácido 2-cloroetil fosfônico (CEPA) contido no produto da Amchem Products Inc. (Ambler, PA.) comercialmente denominado 'Ethrel' (ethephon). Utilizou-se o ácicio giberélico ou $\mathrm{GA}_{3}$ produzido pela Schuchardt Munchen, da Alemanha.

Todos os tratamentos com os reguladores de crescimento foram efetuados através de imersão das panículas na solução contida em recipiente plastificado. Às soluções adicionou-se o espalhante adesivo "Novapal" da Bayer da Alemanha, na dosagem de $0,1 \%$. Trataram-se quatro paniculas uniformes por planta, previamente marcadas com fita de polietileno.

$O$ ensaio foi delineado em blocos casualizados (GOMES, 1963). Realizaram-se 14 tratamentos, sendo distribuidos de foram casual em cada um dos quatro blocos cujas parcelas (representadas por uma planta) para maior homogeneidade, estavam dispostas em linha. Foi de 56 o número de plantas utilizadas no ensaio. Efetuaram-se as análises de variância de acordo com o esquema:

\begin{tabular}{lc}
\hline Causas de Variação & G.L. \\
\hline Blocos & 3 \\
Tratamentos & 13 \\
Resíduo & 39 \\
Total & 55 \\
\hline
\end{tabular}

Procedeu-se a comparação de médias pelo Teste de Tukey, calculando-se a diferen¡̧a mínima significativa (D.M.S.) ao nivel de e $1 \%$ de probabilidade.

Efetuou-se a coleta das panículas por ocasião da colheita final, com a maturação completa das bagas. Nesta colheita retirou-se uma panícula marcada por planta e colozou-se etiqueta de identificação; sendo que as paniculas, cuidadosamente acondicionaJas em sacos de polietileno, foram levadas para uma câmara frigorifica a 50C, onde permaneceram por uma semana, até a avaliação dos dados considerados.

O peso da panícula e das bagas, determinou-se com precisão de 0,1 grama. As medid as de comprimento da ráquis e largura da panícula e do engaço (ráquis + cachos sem bagas) foram obtidas com aproximação de 0,1 centímetro; sendo que o comprimento e largura das bagas, o diâmetro da porção mediana da ráquis e da ráquila, e o comprinento da ráquila, foram tomados com 0,01 centímetro de precisão.

Quanto às análises do suco, verificamos em amostragens de todos os tratamentos, dosagem dos açúcares $(\mathrm{g} / 100 \mathrm{ml})$ através de um refratômetro manual para Brix com J,1 grau de precisão. A acidez total foi avaliada pelo método proposîo pelo Ministério da Agricultura, sendo expressa em $\mathrm{ml}$ de hidróxido de sódio normal por $100 \mathrm{mi}$ do suco. Conhecendo-se o teor de açúcares e a acidez total, calculou-se o Índice de Maturação (açúcares/acidez total). Determinou-se ainda o teor de açúcares redutores $(\mathrm{g} / 100$ ml) pelo método de Eynon - Lane (BROWNE \& ZERBAN, 1941; TOLEDO, 1960). 
Videiras semelhantes em vigor foram selecionadas para tratamentos, em cada linha constituinte do bloco. Os tratamentos foram aplicados em videiras sorteadas dentro de cada um dos quatro blocos.

Aplicaram-se os reguladores de crescimento 14 dias antes do florescimento, em 27 de outubro de 1972. O florescimento máximo ocorreu em 10 de novembro, deste mesmo ano. Alguns tratamentos com ácido giberélico foram concluidos com nova aplicação 10 dias após o florescimento, em 20 de novembro.

Efetuou-se um tratamento-controle e aplicou-se CEPA (ácido 2-cloroetil fosfônico) nas concentrações de 50,100,250,500, 1000 e 2000 ppm. Realizou-se também aplicação de ácido giberálico a $100 \mathrm{ppm}$ em pré-florescimento, em pós-florescimento e em pré e pós-florescimento. Utilizou-se a concentração de $200 \mathrm{ppm}$ de ácido giberélico, em pré-florescimento, em pós-florescimento, e em pré e pós-florescimento. Efetuou-se ainda a aplicação de CEPA 100 ppm + ácido giberélico 100 ppm, em pré-florescimento.

Em 19 de fevereiro de 1973 coletou-se a amostragem de uma panicula tratada por planta, nas 56 videiras, as paniculas foram protegidas e levadas para câmara a 50C. Realizou-se então, em cada panícula, a determinação do peso da panícula, comprimento da panícula, largura da panícula, número de bagas, peso das bagas, comprimento médio das bagas, largura média das bagas, relação comprimento médio/largura média das bagas. Observou-se ainda o comprimento da ráquis, largura do engaço, diâmetro da ráquis, comprimento da ráquila e diâmetro da ráquila. Além disso verificou-se o número de bagas e de sementes. Coletaram-se ainda, amostras de todos os tratamentos com a finalidade de efetuar-se a determinação dos açúcares, acidez total, Índice de Maturação e açúcares redutores.

\section{RESULTADOS E DISCUSSÃo}

QUADRO 1 - Efeitos da aplicação de reguladores de crescimento em 27/10/72, nas frutificações das videiras 'Niagara Rosada' coletadas em 1/2/73 (valores obtidos pelo Teste $F$ para tratamentos e coeficiente de variação em porcentagem).

\begin{tabular}{llr}
\hline Parâmetro & F & C.V.\% \\
\hline \hline Peso da panícula & 1,2737 & 40,56 \\
Comprimento da panícula & $2,1215^{*}$ & 15,80 \\
Largura da panícula & 1,7068 & 12,66 \\
Número de bagas & 1,8402 & 17,37 \\
Peso das bagas & 1,2683 & 40,37 \\
Comprimento médio (C.M.) das bagas & $2,2569^{*}$ & 6,20 \\
Largura média (L.M.) das bagas & $2,8160^{* *}$ & 5,07 \\
Relação C.M./L.M. das bagas & 1,1573 & 2,21 \\
Número de sementes & 1,9707 & 18,80 \\
Comprimento da ráquis & $2,0764^{*}$ & 21,25 \\
Largura do engaço & $1,9813^{*}$ & 17,50 \\
Diâmetro da ráquis & 0,7135 & 21,46 \\
Comprimento da ráquila & 1,2431 & 19,47 \\
Diâmetro da ráquila & 0,4031 & 20,40 \\
\hline
\end{tabular}

\footnotetext{
** Significativo ao nível de $1 \%$.

* Significativo ao nível de $5 \%$.
} 
QUADRO 2 - Relação dos tratamentos efetuados no experimento e respectivas representações das médias.

\begin{tabular}{|c|c|}
\hline Tratamentos & $\begin{array}{c}\text { Representações das } \\
\text { médias }\end{array}$ \\
\hline Testemunha & $\overline{\mathrm{T}}$ \\
\hline CEPA 50 ppm & $\overline{\mathrm{CE}} 50$ \\
\hline CEPA 100 ppm & $\overline{\mathrm{CE}} 100$ \\
\hline CEPA $250 \mathrm{ppm}$ & $\overline{\mathrm{CE}} 250$ \\
\hline CEPA $500 \mathrm{ppm}$ & $\overline{\mathrm{CE}} 500$ \\
\hline CEPA $1000 \mathrm{ppm}$ & $\overline{\mathrm{CE}} 1000$ \\
\hline CEPA $2000 \mathrm{ppm}$ & $\overline{\mathrm{CE}} 2000$ \\
\hline $\mathrm{GA}_{3} 100 \mathrm{ppm}$ pré-antese (I) & $\underline{\mathrm{AG}}$ (I) 100 \\
\hline $\mathrm{GA}_{3} 100 \mathrm{ppm}$ pós-antese (II) & $\overline{\mathrm{AG}}$ (II) 100 \\
\hline $\mathrm{GA}_{3} 100 \mathrm{ppm}$ pré e pós-antese (III) & $\overline{\mathrm{AG}}$ (III) 100 \\
\hline $\mathrm{GA}_{3} 200 \mathrm{ppm}$ pré-antese (I) & $\overline{\mathrm{AG}}$ (I) 200 \\
\hline $\mathrm{JA}_{3} 200 \mathrm{ppm}$ pós-antese (II) & $\overline{\mathrm{AG}}$ (II) 200 \\
\hline${ }^{3} A_{3} 200 \mathrm{ppm}$ pré e pós-antese (III) & $\overline{\mathrm{AG}}$ (III) 200 \\
\hline ZEPA $100 \mathrm{ppm}+\mathrm{GA}_{3} 100 \mathrm{ppm}$ pré-antese (I) & $\overline{\mathrm{CE}} 100+\overline{\mathrm{AG}}$ (I) 100 \\
\hline
\end{tabular}

Resuı tados conseguidos no experımento não apresentaram diferenças significativas com relação ao controle, quanto às características das frutificações.

Os tratamentos comparados entre si revelaram, porém, uma possivel tendência em características favoráveis ou desfavoráveis provocadas pelos reguladores de crescimento nas panículas.

Aplicação do CEPA 250 ppm, resultou na formação de paniculas com a maioria de caracteristicas indesejáveis.

$\mathrm{O}$ tratamento misto CEPA $100+\mathrm{GA}_{3} 100 \mathrm{ppm}$ também promoveu o aparecimento de panículas subdesenvolvidas. Efeitos de toxicidade devido à aplicação de CEPA também foram obtidos por WEAVER \& POOL (1969) aplicando 100 e 1000 ppm do produto na cultivar 'Muscat of Alexandria'.

Aplicação de ácido giberélico 100 ppm 14 dias antes do florescimento e 10 dias após, resultou médias mais elevadas, com relação ao peso da panícula, comprimento da panícula, peso das bagas e comprimento da ráquis. Estes resultados são semelhantes àqueles obtidos por KISHI \& TASAKI (1958), LAVEE (1960) e ANÔNIMO (1967), não apresentando porém os resultados excelentes conseguidos para castas européias por CELESTRE \& PIERANDREI (1969) e TULLIO \& SVAMPA (1970).

Ácido giberélico na concentração de 100 ppm aplicado 10 dias após o florescimento, promoveu uma tendência de aumento nas médias do tratamento quanto ao comprimento médio das bagas, largura média das bagas, largura do engaço e comprimento da ráquila. Isto parece mostrar uma tendência de aumento, principalmente nas dimensões das bagas, devido a aplicação de ácido giberélico após o florescimento. Estes resultados são parcialmente semelhantes àqueles obtidos por SINGH (1961), CAJLAHJAN \& SARKIZOVA (1963); sendo que as diferenças não se mostraram tão evidentes como 


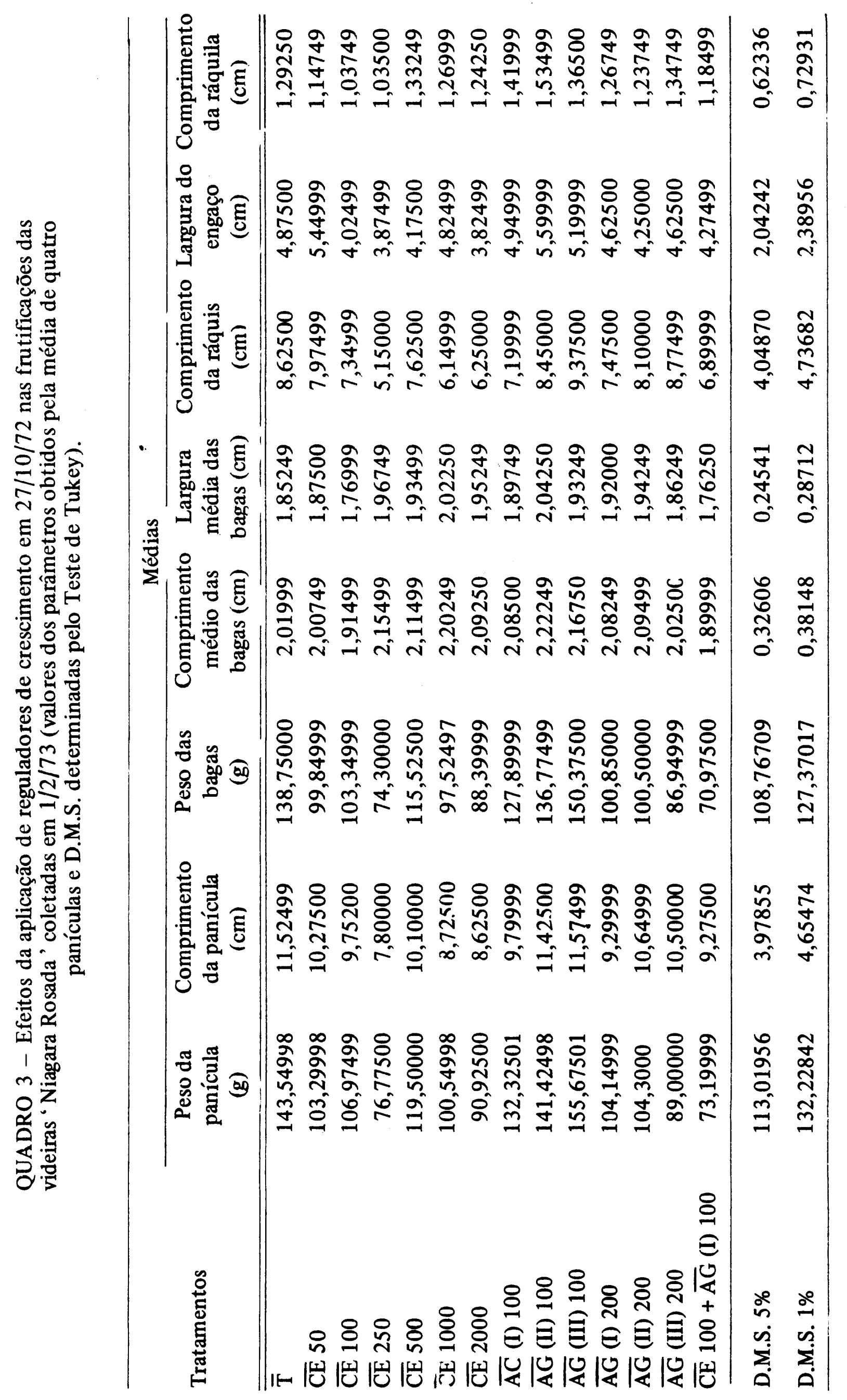


QUADRO 4 - Efeitos da aplicação de reguladores de crescimento em 27/10/72, na dosagem de açúcares $(\mathrm{g} / 100 \mathrm{ml})$, acidez total $(\mathrm{NaOH} 1 \mathrm{~N} / 100 \mathrm{ml})$, Indice de Maturação e açúcares redutores $(\mathrm{g} /$ $/ 100 \mathrm{ml}$ ), em amostragens das frutificaçōes das videiras "Niagara Rosada" coletadas em 1/2/73.

\begin{tabular}{lcccc}
\hline Tratamentrs & Açúcares & $\begin{array}{c}\text { Acidez } \\
\text { Total }\end{array}$ & $\begin{array}{c}\text { Indice de } \\
\text { Maturação }\end{array}$ & $\begin{array}{c}\text { Açúcares } \\
\text { Redutores }\end{array}$ \\
\hline \hline T & 14,1 & 10,6 & 1,330 & 11,67 \\
CE 50 & 14,1 & 11,0 & 1,282 & 10,71 \\
CE 100 & 13,6 & 11,4 & 1,193 & 11,53 \\
CE 250 & 14,1 & 11,0 & 1,282 & 11,53 \\
CE 500 & 14,1 & 12,0 & 1,175 & 11,53 \\
CE 1000 & 13,4 & 10,4 & 1,288 & 11,60 \\
CE 2000 & 13,1 & 12,0 & 1,092 & 11,20 \\
AG (I) 100 & 13,1 & 11,6 & 1,129 & 11,14 \\
AG (II) 100 & 14,4 & 11,4 & 1,263 & 11,88 \\
AG (III) 100 & 14,1 & 11,0 & 1,282 & 11,53 \\
AG (I) 200 & 13,2 & 11,0 & 1,200 & 11,95 \\
AG (II) 200 & 14,9 & 10,2 & 1,461 & 13,07 \\
AG (III) 200 & 13,4 & 12,4 & 1,081 & 11,20 \\
CE 100 + AG (I) 100 & 13,7 & 12,2 & 1,123 & 11,01 \\
\hline
\end{tabular}

aquelas conseguidas com cultivares apirenas por WINKLER (1962), LIDER \& EINSET (1966) e SRIVASTAVA \& BISHT (1969). Por outro lado, CELESTRE (1963) observou diminuição no peso de bagas; sendo que TARANTOLA \& CURZEL (1963) não encontraram efeito de giberelina aplicada em pós-florescimento sobre cultivares para vinho.

As condições de meio ambiente podem ser responsáveis pela limitação das diferenças entre os tratamentos observadas na colheita final (SHOEMAKER, 1948); sendo que PRATT \& SHAULIS (1961) verificaram que bagas tratadas com giberelinas mostraram-se com maiores dimensões três semanas após o florescimento, mas na colheita final apresentaram-se menores que a testemunha.

\section{CONCLUSŌES}

Apesar dos resultados obtidos não apresentarem diferenças significativas com relação ao controle, observou-se uma tendência à formação de panículas com características indesejáveis com aplicação do ácido 2-cloroetil fosfônico na concentração de 250 ppm.

Verificou-se, com a aplicação de ácido giberélico na concentração de 100 ppm, em pré e pós-florescimento, e também em pós-florescimento, a tendência de se obterem panículas com características morfológicas favoráveis. 
SUMMARY

\section{ACTION OF CEPA AND GIBBERELLIC ACID ON FRUITING OF ' NIAGARA ROSADA' GRAPES}

Studies were carried out to establish the effects of exogenous growth regulators on Vitis (labrusca $x$ vinifera) 'Niagara Rosada' fruiting.

The investigations were done in the Jundiai Research Station, Agronomic Institute State of São Paulo, always using disease-free vineyards of good productivity.

The morphological transformations of clusters were carried out under the following aspects: weight, length and width of cluster; number of berries; weight, length average and width average of berries; length average/width average ratio of berries; number of seeds; length and diameter of secondary rachis. That characteristics were determined at the time of maturity plus the total sugars, total acid, Maturity Index and reducing sugars in samples of all treatments.

The experiment were conduced in order to determine the doses that resulted in the most beneficial effects, always using applications by immersion of the inflorescence. The experiment consisted of appplications of (2-chloroethyl) phosphonic acid (CEPA) at concentrations of $50,100,250,500,1,000$ and 2,000 ppm, 14 days before flowering; treatments with gibberellic acid at concentrations of 100 and $200 \mathrm{ppm}$ before full bloom, 10 days after full bloom, and both before plus after full bloom. Treatment with CEPA 100 ppm plus gibberellic acid 100 ppm before full bloom and check treatment were also used.

The use of CEPA before flowering at the concentrations used, did not result in good results in 'Niagara Rosada' clusters; applications of gibberellic acid did not differ significantly from the nontreated vines under the conditions studied.

\section{LITERATURA CITADA}

ANÔNIMO, 1967. Gibberellin Kyowa. Tec. Bull., Japan 1-5.

ARRUDA NETO, J.S., 1970. Cultura da videira, diagnóstico da situação, medidas corretivas. Coord. Ass. Tec. Int., Campinas, 1-69 (mimeografado).

BORZINI, G., 1968. L'azione dell'acido gibberellico sulla fruttificazione della viti. Agricoltura, $17(6): 54-56$.

BROW:F, C.A. \& ZERBAN, F.W., 1941. Physical and chemical methods of sugar analysis. John Wiley \& Sons Inc., New York. 1-1353.

CAJLAHJAN, M.H. \& SARKIZOVA, M.M., 1963. The effect of gibberellin on the growth of the berries on the grape-vine. Dokl. Akad. Nauk. SSSR, 148 219-222.

CELESTRE, M.R., 1963. Effetto dell'acido gibberellico e dell'acido 4-paraclorofenoxiacetico sull'uva 'Ohanez'. Rev. Vitic. Enol., 16(10):359-368.

CELESTRE, M.R. \& PIERANDREI, F., 1969. Effetto dell'acido gibberellico su alcune cultivar di uve da tavola. Italia, 1-17. 
CHRISTODOULOU, A., WEAVER, R.J. \& POOL, R.M., 1968. Relation of gibberellin treatment to fruit-set, berry development, and cluster compactness in Vitis vinifera grapes. Proc. Am. Soc. Hort. Sci., 92:301-310.

CRANE, J.C., 1964. Growth substances in fruit setting and development. Ann. Rev. Plant Physiol., $15: 303-326$.

GALSTON, A.W. \& DAVIES, P.J., 1970. Control mechanisms in plant development. Prentice-Hall, New Jersey 1-184.

GOMES, F.P., 1963. Curso de estatística experimental. Universidade de São Paulo. E.S.A. "Luiz de Queiroz", Piracicaba, 1-384.

HALE, C.R., COOMBE, B.G. \& HAWKER, J.S., 1970. Effects of ethylene and 2-chloroethylphosphonic acid on the ripening of grapes. Plant Physiol., 45 .620-623.

HALL, W.C. \& MORGAN, P.W., 1964. Auxin-ethylene interrelationships. Em: Régulateurs naturels de la croissance végétable. C.N.R.S., Paris, 728-745.

HALSEY, D.D., 1959. Use of gibberellin sprays on grapes. Agr. Ext. Serv. Univ. California, 1-2.

HANSEN, E. \& HARTMAN, E., 1937. Effect of ethylene and metabolic gases upon respiration and ripening of pears before and after cold storage. Plant Physiol., 12.441-454.

HEDRICK, U.P., BOOTH, N.O. \& TAYLOR, O.M., 1908. The grapes of New York. J.B. Lyon Co., Albany, 1-564.

HUSMANN, G.E., 1932. Grapes districts and varieties in the United States. U.S. Dept. Agric. Bull., 1689:1-32.

IWAHORI, S., WEAVER, R.J. \& POOL, R.M., 1968. Gibberellin-like activity in berries of seeded and seedless Tokay grapes. Plant Physiol., 43:333-337.

KISHI, M. \& TASAKI, M., 1958. The effect of gibberellin on grape varieties. Japan Gibberellin Res. Assoc., Tokyo, 13-14.

KRISHNAMURTHI, S., RANDHAWA, G.S. \& SINGH, J.P., 1959. Effect of gibberellic acid on fruit set, size, and quality in the Pusa Seedless variety of grapes (Vitis vinifera L.). Indian J. Hort., $16: 1-4$.

KUROSAWA, E., 1926. Experimental studies on the secretion of Fusarium heterosporum on rice plants. Trans. Nat. Hist. Soc. Formosa, 16:213-227.

LAVEE, S., 1960. Effect of gibberellic acid on seeded grapes. Nature, 185 :395.

LIDER, L.A. \& EINSET, J., 1966. Improving berry and cluster size of seedless New York grapes. Fm. Res., 10-11.

MAXIE, E.C. \& CRANE, J.C., 1968. Effect of ethylene on growth and maturation of the fig, Ficus carica L., fruit. Proc. Am. Soc. Hort. Sci., 92:255-267.

MUNSON, T.V., 1909. Foundations of american grapes culture. Orange Judd Co., New York, $1-252$.

NELJUBOW, D., 1901. Uber die horizontal Nutation der Stengel von Pisum sativum und einiger anderem Pflanzen. Bot. Zbl. Beich., 10 :128-139.

PALEG, L.G., 1965. Physiological effects of gibberellins. Ann. Rev. Plant Physiol., 16:291-322.

PEREIRA, F.M., 1972. Estudo da giberelina sobre a videira 'Niagara Rosada' (Vitis labrusca L. $\mathrm{x}$ Vitis vinifera L.). Tese de Doutoramento. E.S.A. "Luiz de Queiroz", Piracicaba, 1-134.

PRATT, H.K. \& GOESCHL, J.D., 1969. Physiological roles of ethylene in plants. Ann. Rev. Plant Physiol., $20: 541-584$.

PRATT, C. \& SHAULIS‘ N., 1961. Gibberellin induced parthenocarpy in grapes. Proc. Am. Soc. Hort. Sci., $77: 322-330$.

ROWE, J.W., 1968. The common and systematic nomenclature of cyclic diterpenes. Forest Pro- 
ducts Laboratory, U.S. Dept. Agric., Madison.

RUDDAT, M., 1969. Biosynthesis and metabolism of steviol. Em: Biochemistry and physiology of plant growth substances. Ed. F. Wightman \& G. Setterfield. Runge Press, Otawa, 341-346.

SHAULIS, N., 1950. Cultural practices for New York vineyards. New York State Coll. Agr. Bull.. $805: 1-47$.

SHING, K.C., 1961. Effects of gibberellin on the flowering and fruiting of vine. Mem. Coll. Agric. Nath. Taiwan Univ., 6(2):36-41.

SHOEMAKER, J.S., 1948. Small fruit culture. The Blakiston Co., Philadelphia, 1433.

SOUSA, J.S.I., 1959a. Origens do vinhedo paulista. Prefeitura Mun. Jundiaí, 1-319.

SOUSA, J.S.I., 1959b. Mutações somáticas na videira Niagara. Bragantia, 18(27):387-415.

SOUSA, J.S.I., 1969. Uvas para o Brasil. Edições Melhoramentos, São Paulo, 1-454.

SRIVASTAVA, R.P. \& BISHT, D.S., 1969. Effect of gibberellic acid on fruit crops. Hort. Sci. Calcutta, 1(1):39-42.

TARANTOLA, C. \& CURZEL, U., 1963. La gibberelina in vitucultura: resultati di un trieno di spirimentazione su cultivar da vino. Atti Accad. Ital. Viti Vinasiena, 15:1-22.

TOLEDO, O.Z., 1960. Instruções para a fabricação do vinho. Inst. Agr. Est., Campinas, 121:1-68.

TULLIO, U. \& SVAMPA, G., 1970. Azione dell'acido gibberellico nell'acinellatura dei grappoli de vite. Inform. Agron., $5: 444$.

VALADARES, J., LEPSCH, I.F. \& KUPPER, A., 1971. Levantamento pedológico detalhado da Estação Experimental de Jundiaí, SP. Bragantia, 30(25):337-386.

WEAVER, R.J., 1956. Plant regulators in grape production. Calif. Agr. Exptl. Sta. Bull., 752.

WEAVER, R.J., 1972. Plant growth substances in agriculture. W.H. Freeman and Company, San Francisco, 1-594.

WEAVER, R.J. \& McCUNE, S.B., 1959a. Response of certain varieties of Vitis vinifera to gibberellin. Hilgardia, 28 297-350.

WEAVER, R.J. \& McCUNE, S.B., 1959b. Effect of gibberellin on seeded Vitis vinifera and its translocation on within the vine. Hilgardia, 28.625-645.

WEAVER, R.J. \& MONTGOMERY, R.T., 1972. Effect of ethephon on coloration of grapes. Hort. Science, 7(3):322.

WEAVER, R.J. \& OLMO, H.P., 1957. Response of certain varieties of Vitis vinifera grapes to gibberellic acid. Am. Soc. Hort. Sci., 54.48.

WEAVER, R.J. \& POOL, R.M., 1965. Relation of seededness and ringing to gibberellic-like activity in berries of Vitis vinifera. Plant Physiol., 40:770-776.

WEAVER, R.J. \& POOL, R.M., 1969. Effect of ethrel, abscisic acid, and a morphactin on flower and berry abscission and shoot growth in Vitis vinifera. J. Am. Soc. Hort. Sci., 94:474-478.

WEAVER, R.J. \& POOL, R.M., 1971. Berry responce of 'Thompson seedless' and 'Perlette' grapes to application of gibberellic acid. J. Am. Soc. Hort. Sci., $96: 162-166$.

WEAVER, R.J. \& WILLIAMS, W.O., 1950. Response of flowers of Black Corinth and fruit of Thompson Seedless grapes to applications of plant growth-regulators. Bot. Gaz., 111:477-485.

WEST. C.A., OSTER, M., ROBINSON, D., LEW, F. \& MURPH, P., 1969. Biosynthesis of gibberellin precursors and related diterpene. Em: Biochemistry and physiology of plant growth substances. Ed. F. Wightman \& G. Setterfield. Runge Press, Otawa, 313-332.

WINKLER, A.J., 1962. General viticulture. University of California Press, Bekerley, 1-792.

YABUTA, T. \& HAYASHI, T., 1939. Biochemical studies on "bakanae" fungus of rice, II : Isolation of gibberellin, the active principal which produces slender rice seedlings. J. Agr. Chem. Soc. 
Japan, $15 \cdot 257-266$.

YANG, S.F., 1969. Biosynthesis of ethylene. Em: Biochemistry and physiology of plant growth hormones. Ed. F. Wightman \& G. Setterfield. Runge Press, Otawa, 1217-1228.

ZIMMERMANN, P.W. \& WILCOXON, F., 1935. Several chemical growth substances which cause initiation of roots and other responses in plants. Contrib. Boyce Thompson Inst., 7 209-229. 
